\title{
Wild-type transthyretin amyloidosis in female patients
}

\author{
Arnt V Kristen ${ }^{1 *}$, Ralf Bauer ${ }^{1}$, Fabian aus dem Siepen ${ }^{1}$, Christoph Kimmich², Katrin Hinderhofer ${ }^{3}$, Christoph Röcken ${ }^{4}$, \\ Hugo A Katus ${ }^{1}$
}

From First European Congress on Hereditary ATTR amyloidosis

Paris, France. 2-3 November 2015

\section{Background}

Wild-type TTR amyloidosis (wt-ATTR) is a common aging phenomenon in the elderly population. It is claimed to affect exclusively males. Female gender was assumed as a protective factor. Clinical data on wt-ATTR in female gender is lacking. This single center analysis reported on gender differences of clinical variables in wt-ATTR.

\section{Methods}

Patient records of 207 consecutive patients with wt-ATTR were analyzed for clinical variables obtained during the initial assessment at Heidelberg Amyloidosis Center, including electrocardiography, echocardiography, and laboratory results. All variables were compared between male and female gender. Finally, predictors of survival (onset of first symptoms to death) were evaluated.

\section{Results}

Comparison of clinical findings between males and females affected by wt-ATTR amyloidosis are shown in table 1 . Female patients with wt-ATTR did not differ from male patients regarding demographic or clinical parameters except for modified body mass index $(1140 \pm 184$ vs. $1029 \pm 154, \mathrm{p}<0.05)$, glomerular filtration rate $\left(66 \pm 23\right.$ vs. $\left.85 \pm 31 \mathrm{ml} / \mathrm{min}^{*} \mathrm{~m}^{2 *} 1.73 ; \mathrm{p}<0.05\right)$, NYHA class $(2.4 \pm 0.7$ vs. $2.9 \pm 0.3 ; \mathrm{p}<0.01)$ and $\mathrm{PQ}$ interval $(211 \pm 50 \mathrm{~ms}$ vs. $170 \pm 26 ; \mathrm{p}<0.01)$. Interestingly, both groups especially did not differ in age at onset of symptoms, but longer delay between start of symptoms and diagnosis of wt-ATTR in females was observed when compared to male patients with wt-ATTR.

${ }^{1}$ Department of Cardiology, University of Heidelberg, 69120, Heidelberg, Germany

Full list of author information is available at the end of the article
In total, 6 deaths (35\%) occurred in females and 45 deaths $(24 \%)$ in males. No gender differences were observed regarding mean survival (females $54 \pm 35$ month, males $56 \pm 107$ months). By multivariate analysis independent predictors of mortality in the whole cohort were use of diuretics (HR 8.657, 95\%CI 1.160-64.17; $\mathrm{p}=0.035)$ and hs-TnT (HR 1.009, 95\%CI 1.004-1.015; $\mathrm{p}=0.001)$.

In total, 6 deaths (35\%) occurred in females and 45 deaths $(24 \%)$ in males. No gender differences were observed regarding mean survival (females $54 \pm 35$ month, males $56 \pm 107$ months). By multivariate analysis independent predictors of mortality in the whole cohort were use of diuretics (HR 8.657, 95\%CI 1.160-64.17; $\mathrm{p}=0.035)$ and hs-TnT (HR 1.009, 95\%CI 1.004-1.015; $\mathrm{p}=0.001$ ).

\section{Conclusion}

Although wt-ATTR is claimed to be a disease of male gender there is a considerable number of females affected with cardiac manifestation of wt-ATTR. According to this first report on clinical characteristics of a relatively well sized cohort of females no gender-specific differences regarding clinical characteristics and median survival were observed, except for modified body mass index and PQ interval as well as higher glomerular filtration rate and NYHA class in female patients. Moreover, use of diuretics and hs-TnT appeared to be predictors of mortality.

\section{Authors' details}

${ }^{1}$ Department of Cardiology, University of Heidelberg, 69120, Heidelberg, Germany. ${ }^{2}$ Department of Hematology, University of Heidelberg, 69120, Heidelberg, Germany. ${ }^{3}$ Institute of Human Genetics, University of Heidelberg, 69120, Heidelberg, Germany. ${ }^{4}$ Institute of Pathology, University of Kiel, 24105, Kiel, Germany. 
doi:10.1186/1750-1172-10-S1-O9

Cite this article as: Kristen et al:: Wild-type transthyretin amyloidosis in

female patients. Orphanet Journal of Rare Diseases 2015 10(Suppl 1):09.

Submit your next manuscript to BioMed Central and take full advantage of:

- Convenient online submission

- Thorough peer review

- No space constraints or color figure charges

- Immediate publication on acceptance

- Inclusion in PubMed, CAS, Scopus and Google Scholar

- Research which is freely available for redistribution

Submit your manuscript at 